\title{
The dynamics of the relationship between just-for-fun online harassment and perceived school safety
}

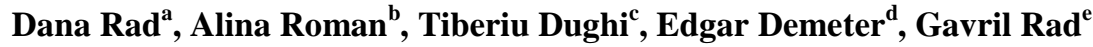

${ }^{a}$ Faculty of Educational Sciences, Psychology and Social Sciences, Aurel Vlaicu University of Arad, Arad, Romania,dana@xhouse.ro, ${ }^{\text {b}}$ Faculty of Educational Sciences, Psychology and Social Sciences, Aurel Vlaicu University of Arad, Arad, Romania, romanalinafelicia@yahoo.com, ${ }^{\mathrm{c}}$ Faculty of Educational Sciences, Psychology and Social Sciences, Aurel Vlaicu University of Arad, Arad, Romania, tibi_dughi@yahoo.com, ${ }^{\mathrm{d}}$ Faculty of of Educational Sciences, Psychology and Social Sciences, Aurel Vlaicu University of Arad, Arad, Romania, eddemeter@yahoo.com, ${ }^{\mathrm{e}}$ Faculty of of Educational Sciences, Psychology and Social Sciences, Aurel Vlaicu University of Arad, Arad, Romania,rad.gabi@yahoo.com.
\end{abstract}

\begin{abstract}
Based on previous analysis needs, our expert team has implemented the project Keeping youth safe from Cyberbullying financed by Erasmus+ KA2, focusing on the in-depth dynamics analysis of the cyberbullying phenomenon that unfortunately has become more and more present in youth online environments. Our team has designed an online questionnaire with the purpose of collecting descriptive data about youth participants, general perception about the cyberbullying particularity incidents, perceived safety of the educational setting and perceived parental support, and lastly a selfrating evaluation scale on self-efficacy perceptions. A total of 92 participants voluntarily responded to. Present research's focus is the analysis of the association between just-for-fun online harassment type of cyberbullying and youth perceived school safety. Our team has used a curvilinear regression analysis for depicting curvilinear effects, in order to test the hypothesis assuming the curvilinear relationship between youth perceived school safety and just-for-fun online harassment type of cyberbullying. Results confirm the curvilinear relationship, implying the fact that the weaker and as well as the stronger educational context safety is perceived, just-for-fun online harassment type of cyberbullying is present in school; a medium/normal school safety perception triggers a lower just-for-fun online harassment type of cyberbullying incidence in youth. Authors further discuss the implications of these findings, in terms of cyberbullying prevention strategies.
\end{abstract}


Keywords: perceived school safety, just-for-fun online harassment, cyberbullying, curvilinear relationship.

\section{Introduction}

Cyberbullying takes part to a bigger phenomenon that was present before the development of social media, such as bullying which is described as an aggressive behavior, usually characterized by the following aspects: hostile intentions, imbalance of perceived power, and repetition of the hostile behavior (Burger et al., 2015). In this light, bullying can be described as the activity of repeated and aggressive behavior intended to hurt and to humiliate another person, physically, mentally or emotionally.

As the modern civilization developed more and more, bullying started happening while using technological devices as tools to express hostile intentions to other individuals; bullying while using technological devices is known as cyberbullying, a form of aggression used in the online environment, which implies repeated behaviors that have the intention to harm one or more individuals (Willard, 2005). These behaviors may be represented by posting negative rumors, threats, remarks with sexual content or personal information in the form of comments or messages, which can humiliate or cause harm to the victim (US Legal, https://definitions.uslegal.com/c/cyber-bullying/).

In 1993, Olweus has identified the traits of youth being more susceptible to being either perpetrators, either victims, such as:

Aggressors tend to manifests the need to dominate other persons. Their psychological profile is characterized by impulsiveness, provocativeness, easily annoyed, not following the rules and having an over-rated self-image.

Victims' psychological profile: passive in behavior and communication, tendency to isolate themselves from the society, cautiousness, sensitiveness, withdrawn tendency, shyness, manifesting insecurities, high levels of anxiety, decreased self-esteem, usually perceived as inapt of defending themselves, and in general not taking any action to stop the perpetrator or the aggression.

One of the reasons for cyber-bullying that are discussed in the literature is the fun factor, which can motivate adolescents to engage in cyber-bullying (Patchin \& Hinduja, 2010; Kyriacou \& Zuin, 2016; Compton et al., 2014; Smith et al., 2008). Similar to traditional bullying, the fun factor serves as a good motivator for engaging in cyberbullying aiming to entertain one self and peers, regardless victim's wellbeing,, more often in asynchrony contexts. It is stated in literature that in the case of non-physical contact, then the 
perpetrator's level of empathy is known to be decreased (Smith et al., 2008). As regard to Olweus (1993) descriptions, the aggressor is more likely to engage in just for fun bullying because they are more likely to see the fun factor as a good motive to engage in this kind of actions (because they feel more superior and they see their actions as justifiable).

Explanations on cyberbullying are also brought by social interconnections and peer influence. A study evidenced that the chances of becoming a victim of cyberbullying are increased when socio-anxiety, interpersonal communication deficiencies to with friends and in general with the social group, and also the lack of appropriate social skills are present. (Betts, 2016; Navarro et al., 2012). Since the vast internet is able to provide anonymity the perceived perpetrator and victim roles may dramatically interchange in the virtual realm (Wilton \& Campbell, 2011). The perpetrator can be any person and in most of the cases they are not physically robust, so they might instead be the victims of classical bullying, caught in an acting negative spiral of revenge (Compton, L., Campbell, M.A., \& Mergler, A., 2014) towards anybody who mistreated them. Perceived anonymity eliminates social judgment in the peer group along with any other concern of being disposed or disapproved (Wilton\& Campbell, 2011; Willard, 2005).

One important reason of the bullying and cyberbullying phenomenon discussed in literature is victimization (Akbulut, 2010; Wilton \& Campbell, 2011). Therefore, some individuals who became victims have the tendency to bully other people in school or cyberspace with the purpose of coping with the victimization psychological context and enhance the better feeling about themselves. In this light, studies from literature showed that the perceived school climate can be a good predictor in traditional bullying and cyberbullying (Casas, J.A., Del Rey, R. Ortega-Ruiz, R., 2013; Ortega-Barón, J., Buelga, S., Cava, M.-J., 2016). For instance, a research showed that youth who experienced cyberbullying in both perpetrator and victim situations, perceived a weaker climate or poorer educational when compared to youth that did not experience cyberbullying (Cyberbullying Research Center, 2010).

\section{Research methodology}

Based on previous analysis needs, our expert team has implemented the project Keeping youth safe from Cyberbullying financed by Erasmus+ KA2, focusing on the in-depth dynamics analysis of the cyberbullying phenomenon that unfortunately has become more and more present in youth online environments. Our team has designed an online questionnaire with seven sections with the purpose of collecting descriptive data about youth participants, general perception about the cyberbullying particularity incidents, 
perceived safety of the educational setting and perceived parental support and lastly a selfrating evaluation scale on self-efficacy perceptions. This research's interest is to take a closer look and to analyze the dynamics characterizing the cyberbullying situations, taking into account youth perceived just-for-fun online harassment acting.

This paper is concerned with analyzing the relationship between just-for-fun online harassment and perceived school safety, with regards to the fact that the scientific literature depicts implications on cyberbullying behavior based on how safe the educational environment feels like to youth.

The two self-rated single items that assessed perceived school safety and just-for-fun online harassment are: Item 14 - "Please rate on a 1 to 5 scale how safe is your school?", where $1=$ strong disagreement and 5 = strong agreement with the statement; Item $\mathbf{2 8}$ - Please respond with YES or NOT to the following question: "Did you ever online harassed somebody, together with your peers, with the purpose of just having fun?"

When analyzing the relationship between perceived just-for-fun online harassment and school safety, our team has assumed that the single-item research variables are in a curvilinear relationship. Thus, with the purpose of testing the curvilinear hypothesis, we have computed a quadratic regression analysis for depicting curvilinear effects, considering the dependent variable just-for-fun online harassment.

The research targeted a heterogeneous random sample of 92yoth participants with a range of ages between 18 and 30, 10,9\% being masculine and 89,1\% feminine, coming from both urban and rural. Regarding sample's level of education, 63\% finished high-school, 22,8\% have a bachelor and $14,2 \%$ have a master diploma. The majority of sample target group, $68.2 \%$ have between 1 to 3 years online experience with different social media environments.

\section{Results}

With the purpose of statistically testing our assumption stating that just-for-fun online harassment and perceived school safety are in a curvilinear relationship, we have computed a quadratic regression analysis for depicting curvilinear significant effects.

Consistent with the scientific literature conclusions, in a curvilinear relationships variables are both growing in the same direction up to a specific point, statistically depicted as a positive correlation. After reaching this point, one of the variables starts to decrease, meanwhile the second variable continues to increase, depicted as a negative correlation significant coefficient. 
We have calculated a high correlation coefficient between Item 28 just-for-fun online harassment with a $\mathrm{MD}=1.03$, and $\mathrm{SD}=0.179$ and Item 14 youth perceived school safety $(\mathrm{MD}=4.64, \mathrm{SD}=0.656)$ of $\mathrm{r}=-0.368$ significant at a $\mathrm{p}<0.01$, result that gives us incentives in further implementing the curvilinear regression analysis. In the present quadratic model of regression, the DV is just-for-fun online harassment, and the independent variable included in the $1^{\text {st }}$ step perceived school safety, and in the $2^{\text {nd }}$ step squared perceived school safety.

In Table 1 there is presented the fitting coefficients of both our computed regression models, linear (1) and quadratic (2). As depicted in the $1^{\text {st }}$ Model, the one that assumes a linear relationship, the variable just-for-fun online harassment is accountable for $12 \%$ of the variance in perceived school safety $(F=14.103$ significant at a $p<0.01)$. In the $2^{\text {nd }}$ Model, assuming a curvilinear relationship, the variable just-for-fun online harassment is accountable for $33 \%$ of the variance in perceived school $(\mathrm{F}=28.748$ significant at a $\mathrm{p}<$ $0.01)$.

Table 1. Regression models for just-for-fun online harassment and perceived school safety.

\begin{tabular}{|c|c|c|c|c|c|c|c|c|c|}
\hline \multicolumn{10}{|c|}{ Descriptive Statistics } \\
\hline & & & \multicolumn{2}{|l|}{ Mean } & \multicolumn{2}{|c|}{ Std. Deviation } & \multicolumn{2}{|c|}{$N$} & \\
\hline \multicolumn{3}{|c|}{ Item 28} & \multicolumn{2}{|l|}{1.03} & \multicolumn{2}{|c|}{.179} & \multicolumn{2}{|c|}{90} & \\
\hline \multicolumn{3}{|c|}{ Item 14 - perceived school safety } & \multicolumn{2}{|l|}{4.64} & \multicolumn{2}{|l|}{.656} & \multicolumn{2}{|c|}{89} & \\
\hline \multicolumn{3}{|c|}{ Perceived school safety sqrt } & \multicolumn{2}{|l|}{21.9674} & \multicolumn{2}{|l|}{5.33380} & \multicolumn{2}{|c|}{89} & \\
\hline \multicolumn{10}{|c|}{ Model Summary } \\
\hline \multirow[t]{2}{*}{ Model } & \multirow[t]{2}{*}{$\boldsymbol{R}$} & \multirow{2}{*}{$\begin{array}{c}R \\
\text { Square }\end{array}$} & \multirow{2}{*}{$\begin{array}{c}\text { Adjusted } \\
R \\
\text { Square }\end{array}$} & \multirow{2}{*}{$\begin{array}{l}\text { Std. } \\
\text { Error of } \\
\text { the } \\
\text { Estimate }\end{array}$} & \multicolumn{5}{|c|}{ Change Statistics } \\
\hline & & & & & $\begin{array}{c}R \\
\text { Square } \\
\text { Change }\end{array}$ & $\begin{array}{c}F \\
\text { Change }\end{array}$ & $d f 1$ & $d f 2$ & $\begin{array}{c}\text { Sig. F } \\
\text { Change }\end{array}$ \\
\hline 1 & $.368^{\mathrm{a}}$ & .135 & .126 & .167 & .135 & 14.103 & 1 & 90 & .000 \\
\hline 2 & $.589^{b}$ & .347 & .332 & .146 & .211 & 28.748 & 1 & 89 & .000 \\
\hline \multicolumn{10}{|c|}{ a. Predictors: (Constant), Perceived school safety } \\
\hline \multicolumn{10}{|c|}{ b. Predictors: (Constant), Perceived school safety, Perceived school safety_sqrt } \\
\hline
\end{tabular}




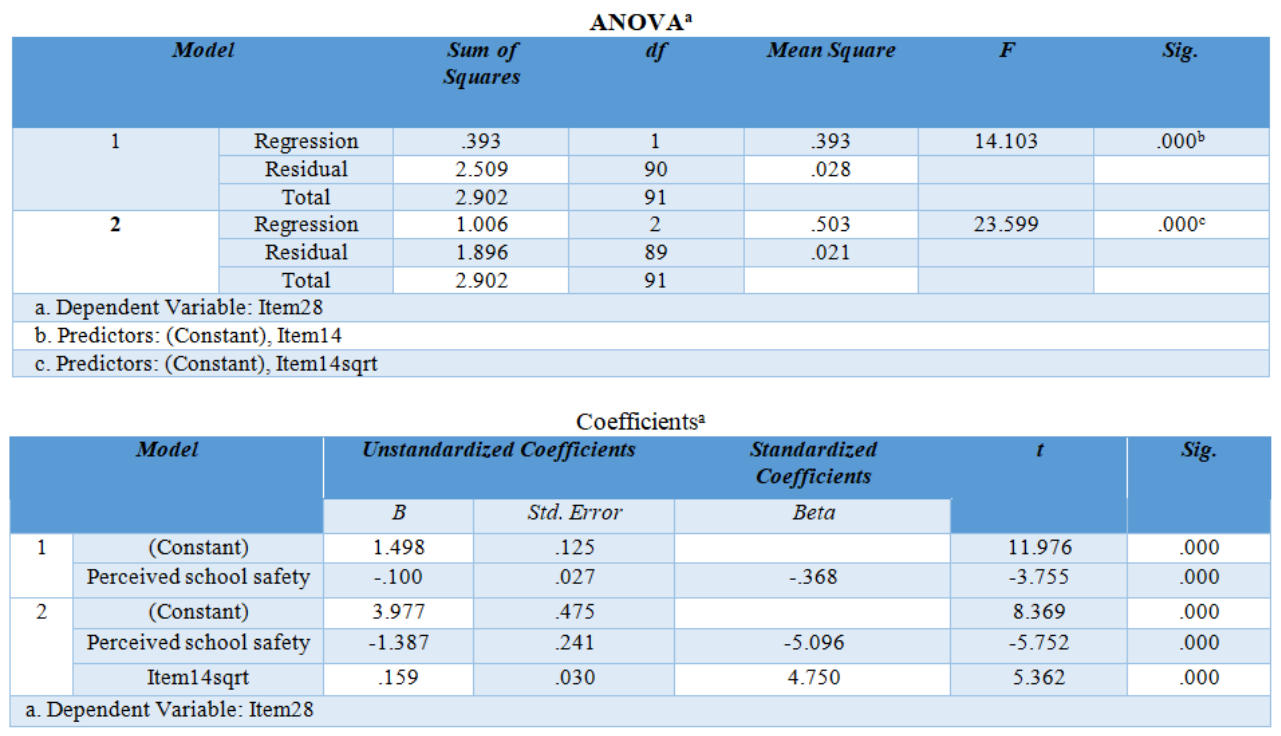

All computed Beta standardized coefficients $(B=-0.368, B=-5.096, B=4.750)$ prove to be statistically significant at $\mathrm{p}<0.01$ providing high consistency to both linear (1) and quadratic (2) models. The switch from positive to negative of the Beta coefficient sign shows that the effect develops in the opposite direction, which clearly illustrates the curvilinear relationship between online just-for-fun bullying and perceived school safety. And finally, the adding of $11 \%$ predictive capacity by including the squared perceived school safety variable known to be responsible for the curve in the regression line, depict once more the consistency optimization of the model supporting the assumption of the curvilinear relationship between just-for-fun online harassment and perceived school safety.

\section{Conclusions and discussions}

The relational educational climate is present in all the theoretical literature, be it the relational climate between the equal, and the teacher-student relations, or between the school management and the teachers. The concept of relational educational climate is one of the central elements in our study.

The school climate is analyzed in terms of its positive and negative aspects: a positive school climate is characterized by the positive management of school unit, positive relationships between teachers, positive relationships between teachers and students, positive relationships between peers and school opening to the community, along with the 
negative climate that is built up in antithesis with the positive one. The effects of the school climate are multiple, at behavioral, cognitive, affective, attitudinal and motivational levels. A positive school climate supports adaptive, socially accepted behaviors and discourages the adoption of risk behaviors.

The school climate has also been seen as a determining factor in school behaviors, including behavioral problems like harassment, aggression and delinquency and health issues like psychosomatic symptoms and substance abuse. All these effects influence each other and directly and indirectly affect school success. Among the factors influencing the perception of the school climate are the gender, the socio-economic background of pupils, the pupils 'competitiveness, and their satisfaction with the school and the level of stress generated by the teachers' expectations.

School climate studies prove that elementary and middle school students are more satisfied with school safety than the high school students. As pupils go further into the school system, they become more bloated, which leads to their increasing dissatisfaction with school and a poor perception of the educational setting climate. On the other hand, as they enter the educational cycle, the expectations of the pupils towards school increase and the latter does not meet their desires, resulting in a new source of dissatisfaction and an unfavorable perception of the school climate.

Current's study curvilinear relationship shows that the weaker and as well as the stronger educational context safety is perceived, just-for-fun online harassment type of cyberbullying is present in school; a medium/normal school safety perception triggers a lower just-for-fun online harassment type of cyberbullying incidence in youth..

Up to now, our research members are unaware of other published results indicating a curvilinear relationship between just-for-fun online harassment and perceived school safety. Our research conclusions might be useful in enhancing knowledge on the dynamical aspects of cyberbullying incidents.

\section{References}

Akbulut, Y., Sahin, Y.L., \& Eristi, B. (2010). Cyberbullying Victimization among Turkish Online Social Utility Members. Educational Technology \& Society, 13 (4): 192-201.

Betts, L.R. (2016). Cyberbullying: Approaches, Consequences and Interventions. UK: Palgrave Macmillan.

Burger, C., Strohmeier, D., Spröber, N., Bauman, S., \& Rigby, K. (2015). How teachers respond to school bullying: An examination of self-reported intervention strategy use, moderator effects, and concurrent use of multiple strategies. Teaching and Teacher Education, 51: 191-202. 
Casas, J.A., Del Rey, R. Ortega-Ruiz, R. (2013). Bullying and cyberbullying: Convergent and divergent predictor variables. Computers in Human Behavior 29: 580-587.

Compton, L., Campbell, M.A., \& Mergler, A. (2014). Teacher, parent and student perceptions of the motives of cyberbullies. Social Psychology of Education, 17(3): 383-400.

Cyberbullying Research Center (2010). Cyberbullying and School Climate. Retrieved from https://cyberbullying.org/cyberbullying-and-school-climate on 04 November 2017.

Kyriacou, C., \&Zuin, A. (2016). Cyberbullying and moral disengagement: an analysis based on a social pedagogy of pastoral care in schools. An International Journal of Personal, Social and Emotional Development, 34(1): 34-42.

Navarro, R., Yubero, S., Larrañaga, E., Martínez, V. (2012). Children's Cyberbullying Victimization: Associations with Social Anxiety and Social Competence in a Spanish Sample. Child Indicators Research, 5(2): 281-295.

Olweus, D. (1993). Bullying at school: What we know and what we can do. Cambridge, MA: Blackwell Publishers, Inc.

Ortega-Barón, J., Buelga, S., Cava, M.-J. (2016). The Influence of School Climate and Family Climate among Adolescents Victims of Cyberbullying. Comunicar, 24(46): 57-65.

Patchin, J.W., Hinduja, S. (2010). Cyberbullying and Self-Esteem. Journal of School Health, 80(12): 614-621.

Smith, P.K., Mahdavi, J., Carvalho, M., Fisher, S., Russell, S., \&Tippett, N. (2008). Cyberbullying: its nature and impact in secondary school pupils. Journal of Child Psychology and Psychiatry, 49(4): 376-385.

US Legal. Cyber Bullying Law and Legal Definition. Retrieved from https://definitions.uslegal.com/c/cyber-bullying/ on 03 November 2017.

Willard, N.E. (2007). Cyberbullying and cyberthreats: Responding to the challenge of online social aggression, threats, and distress. Champaign, IL: Research Press.

Wilton, C., \& Campbell, M. (2011). An exploration of the reasons why adolescents engage in traditional and cyber bullying. Journal of Educational Sciences \& Psychology, 1(2): 101-109. 